\title{
E.J. Lowe on the Unity Problem
}

\author{
Travis Dumsday \\ Department of Philosophy \& Religious Studies, Concordia University College of \\ Alberta
}

Some properties are connected in a perspicuous and unproblematic way. For instance, the possession of shape clearly entails the possession of size (and vice versa). In other cases the connection is not so perspicuous. For instance, assuming that the precise rest mass and negative charge of an electron are both among its fundamental intrinsic properties, what links them, given that those properties are inherently separable? (Their separability is apparent from the fact that other kinds of particle have the same mass as an electron but a different charge, or the same charge but a different mass.) Given the inherent separability of those properties, what explains their conjunction in this case? Oderberg $(2007,2011)$ calls this the "unity problem", and attempts to solve it have issued from assorted schools of thought within both substance ontology and the metaphysics of natural kinds. One of the more significant of these solutions is proffered by E.J. Lowe as part of his four-category ontology. Here I explicate his solution, raise a possible objection, and suggest a reply.

Keywords: substance, kind, nature, essentialism, essence, properties

\section{Introduction}

Some properties are connected / conjoined / associated / tied together in a manner that seems entirely clear and unproblematic. It is no mystery why shape is associated with size, since shape entails size (and vice versa). Similarly, it is clear that there is a necessary tie between being very annoying and being annoying, or between being red and being coloured. (Though in each of those three examples the precise nature of the necessary connection differs.) In many other cases though, the reason for a connection is not so clear. Sometimes properties are associated despite a lack of any obvious necessary link between them, or even despite being obviously inherently separable. What accounts for the connection in cases like that?

Corresponding author's address: Travis Dumsday, Concordia University College of Alberta, 7128 Ada Blvd. Edmonton, AB, T5B 4E4, Canada. Email: travis.dumsday@concordia.ab.ca. 
Note that this question is most pressing when the inherently separable properties under consideration are fundamental and intrinsic to whatever object $^{1}$ they are associated with-or in other words, when the properties under consideration are what advocates of natural-kind essentialism simply call the essential properties of the object. ${ }^{2}$ To see why the question is most pressing for such properties, consider by contrast the precise weight and friendliness of a cat. These are both accidental properties of a cat, properties that could change even while the cat remains a cat. It can gain a bit of weight and still remain a cat, and it can acquire or lose a particular sort of temperament and still remain a cat. Moreover it seems no great mystery how this precise weight and temperament are conjoined in this cat, even though they are inherently separable properties (such that the cat could gain or lose some weight and retain its friendliness, or lose its friendliness without changing weight, and such that the same weight could be found in a different cat but absent the friendliness). This is because their presence is explained by reference to more fundamental properties of the cat, and to past causal processes in which it has been implicated. Its temperament for instance is wholly explained in terms of certain underlying physiological properties and past causal processes (assuming one is not a dualist with respect to cats), as is its present precise weight. The conjunction of properties of that sort, of accidental properties, is generally unproblematic despite their being inherently separable, since their conjunction is explicable by reference to fundamental properties and processes.

The question of how otherwise separable properties are conjoined is thus most difficult, and most interesting, when framed with respect to a thing's essential properties. For instance, the cat is both alive and sentient. Assume for the sake of argument (perhaps implausibly) that these are essential properties of the cat, irreducible to any more fundamental properties. Some things are alive without being sentient (ex. mushrooms), and at least hypothetically some are sentient without being literally alive in the biological sense (ex. angels, Cartesian egos). These properties are essential to the cat, yet are inherently separable. What then explains their conjunction? Or to shift from a biological example to one from physics, consider the electron. For any particular electron, one might ask how its diverse seemingly fundamental intrinsic properties (its essential properties), including negative charge,

For the present I take 'object' here quite broadly to indicate any independently existent entity, on whatever background substance ontology one subscribes to (including bundle theory, according to which an independently existing trope or bundle of tropes might be thought of as an object).

2 See (Gorman 2005) and (Williams and Charles 2013) for some recent accounts of essential properties understood at least in part as fundamental intrinsic properties, properties whose presence in an object is not explained by the object's other properties. 
half-integral spin, and the precise rest mass of $9.109 \times 10^{-28}$ grams, are coinstantiated. After all, some of these properties lack any internally necessary connection one to the other, qua property; this is apparent from the fact that other particles have the same negative charge as an electron but a different mass (tau leptons, for instance) while still others share the same mass as an electron but are positively charged (positrons). And yet despite inherent separability, an ability to be instantiated apart from one another, we find certain properties conjoined. What accounts for that conjunction? Dumsday (2010) refers to this as the 'problem of complex essences', while Oderberg (2007, 2011) labels it the 'unity problem.'

Solutions to the unity problem have been put forward from a number of different schools of thought within substance ontology and the metaphysics of natural kinds. For instance, advocates of substratum theory argue that it can be addressed by reference to the reality of substrata: multiple inherently separable properties get linked by being instantiated in one and the same substratum. ${ }^{4}$ Thus the negative charge and precise rest mass of an electron are linked because, in the case of those objects we label 'electrons', those properties happen to be co-instantiated in the same substratum. Or consider bundle theory, the advocates of which have accounted for the unity problem in a number of ways: primitive compresence relations, mereological fusion, co-location, etc. Or think of Scholastics like Oderberg (2007, 2011), who address it by reference to a version of natural-kind essentialism linked with a hylomorphic substance ontology. On this view, a kind-essence (or,

3 Note that this problem is distinct from the problem of what unifies a composite object's constituent proper parts, insofar as the unity problem can apply even to fundamental objects (i.e., objects with no actual proper parts). It is worth noting though that some solutions to the unity problem have also been thought applicable in some way to the composition issue; for example, historically many Scholastics have argued that substantial form explains both property unification and unity of proper parts. And see (Scaltsas 1994, 61-77 and 150-154) for an argument to the effect that Aristotle himself took substantial form to play both explanatory roles.

${ }^{4}$ For an example of this see (LaBossiere 1994, 364): "It seems reasonable to accept that anything which can affect or be affected must be real. Since the binding of tropes together and the ordering of them to form complex entities clearly seem to be instances of affective activity, it seems reasonable to accept a real binder.... A bundle theorist can agree that there are real beings involved in the binding of tropes while rejecting the claim that the real binders are substrata.... In order to do this, the bundle theorist would argue that there are binding tropes which serve to bind tropes together... But, if each binding trope must be bound by another binding trope an infinite regress will arise and this regress creates two serious problems..." The two problems he alludes to are that (1) infinite regresses of this sort seem unable to provide an adequate causal explanation of any state of affairs, and (2) that it is uneconomical to suppose an infinite number of tropes underlying every single instance of trope binding. At any rate, his basic idea is that substrata can do the necessary unifying work and that a chief competitor, bundle theory, cannot. 
to use more traditional Scholastic terminology, a substantial form) is conceived as an ontologically simple substance-universal whose instantiation in / actualization of a primitive substantial potency (prime matter), entails the characterization of that matter by a coherent set of essential properties. ${ }^{5}$ For instance the substantial form 'electron', the simple substance-universal that constitutes the inner nature of this natural kind, entails by its instantiation in prime matter the presence of negative charge, half-integral spin etc. ${ }^{6}$ According to Oderberg $(2007,142)$, just this sort of unifying kind-essence / substantial form, one that is ontologically prior to its associated essential properties, must be posited in order to address the unity problem: "Some philosophers...think that we can get by with talk of powers without having to ground them ultimately in essence. Or, if they are partial to essences, they would reduce them (without eliminating them) to collections of powers... Yet this takes us back to the unity problem... If to be a K just is to have a collection of powers, then what unites the powers?" Oderberg here draws attention to a distinction worth keeping in mind, a distinction between two versions of natural-kind essentialism: what I will call 'identity NKE', according to which a kind-essence is just a collection of properties, versus what might be termed 'priority NKE', according to which a kind-essence is a universal that in some way entails or otherwise grounds a collection of properties. (As we'll see, Lowe is a proponent of priority NKE, though a different formulation of priority NKE than that advocated by Oderberg.)

All of those approaches (and still others I have not mentioned) have their

5 Consider for instance Kronen's $(1991,130)$ summary of the hylomorphism of the prominent early modern Scholastic, Francisco Suarez: "For Suarez, substantial form is defined as a certain simple entity, substantial in nature... which in material substances determines the matter of the substance to being such and such, where 'matter' is taken to refer to the primal potential stuff and subject of all material changes. It is likewise... that which gives rise to, grounds, and unifies, the various properties and accidents of the substance."

6 As Connell $(1966,152)$, a contemporary Scholastic, puts it: "If an electron is an elementary body, then its particular characteristics have their ground in the substantial form... which, along with the primary matter, constitutes the electron's substance..." Given an understanding of essential properties as fundamental intrinsic properties, would this mean that on the Scholastic view negative charge is not literally essential to the kind 'electron'? After all, charge is here proposed as being grounded in something more fundamental, the substantial form, and as we saw above, Gorman (2005) and others argue that part of being an essential property is being ungrounded in more fundamental properties. In response I would argue that the Scholastic view does allow for properties like negative charge to be essential, even on Gorman's formulation of 'essential'. For on that formulation, a property is essential when its presence is not explained by the presence of a more fundamental property. And according to the Scholastic picture, the kind-essence / substantial form is not a property (in the sense of a characteristic / mode / feature, which is what I take Gorman to intend by 'property'), but rather a substance-universal. So strictly speaking, there is no conflict in formulation here. 
strengths and weaknesses. One interesting and promising solution arises out of the neo-Aristotelian four-category ontology advocated by E.J. Lowe. While Lowe's system has been subjected to a great deal of scrutiny in the recent literature, not much attention has been paid to his treatment of the unity problem. In the remainder of the paper I intend to rectify that. In the next section I provide an explication of Lowe's solution to the unity problem, along the way reviewing relevant portions of his four-category ontology. Then in section three I present a potential objection to his solution, and in section four canvass a possible reply. That reply involves a reformulation of part of Lowe's system; however, I will make the case that it involves no radical alteration of that system, remaining consistent with its core commitments.

\section{Lowe's Solution to the Unity Problem}

According to Lowe, the four fundamental ${ }^{7}$ ontological categories are those of objects (individual substances like Tibbles the cat or Bob the particular electron), kinds (substance-universals like 'felinity' or 'electron'), modes (tropes / individual properties like the redness of Tibbles or the negative charge of this particular electron), and attributes (property-universals like 'redness' or 'negative charge'). Objects are characterized by modes, a basic internal relationship ${ }^{8}$ that is exactly mirrored at the level of universals, such that kinds are characterized by attributes. Thus, just as the particular electron is characterized by the mode that is negative charge, so the kind 'electron' is characterized by the attribute that is 'negative charge'. Another parallel relationship is that of instantiation between kinds and objects on the one hand, and the instantiation relationship between attributes and modes on the other; finally, objects exemplify attributes. This produces Lowe's ontological square (Lowe 2006, 18): ${ }^{9}$

7 See for instance (Lowe 2013, 200): “...I regard these four as the fundamental ontological categories, allowing that within each there may be various sub-categories, sub-subcategories, and so on."

${ }^{8}$ Lowe consciously prefers to use 'relationship' instead of 'relation' when discussing these; see (Lowe 2006, 30) for the reasoning behind this preference.

9 Image used by permission of Oxford University Press. This OUP material is view only and does not come under a Creative Commons license (http://creativecommons.org/licenses/), or any other open access licence, that would allow reuse without requiring permission from OUP. 


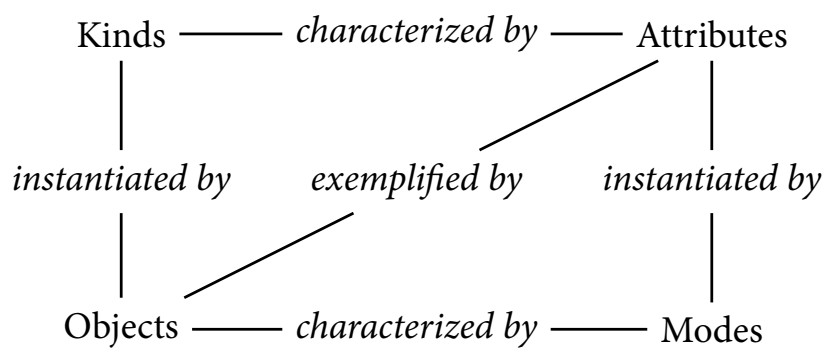

Objects have an ontological priority over and against their modes insofar as modes are both existentially dependent on the objects to which they belong, and identity dependent on those objects. That is, the negative charge of a particular electron could not possibly exist independently of that electron (thus there are no free-floating tropes, contra some bundle theorists), and furthermore the identity of that instance of negative charge presupposes the identity of the particular electron it belongs to. ${ }^{10}$ Objects also have ontological priority over the kinds they instantiate, since the kinds are existentially dependent on the objects (i.e., there are no uninstantiated, Platonic universals), though in a slightly different way kinds are also prior to objects, insofar as an object cannot exist without instantiating some kind. ${ }^{11}$ An object is itself an independently existent entity, logically dependent for its identity on no other distinct object. ${ }^{12}$

Lowe's ontology of substance can properly be classified as a version of primitive substance theory. Advocates of this view deny that a substance is constructed out of more basic metaphysical constituents, whether properties alone (as on bundle theory) or substratum + properties (as on substratum theory) or prime matter + substantial form (as on hylomorphism). Instead,

${ }^{10}$ For an argument in favour of modes having both types of dependence on objects, see (Lowe 1997, 37-40).

${ }^{11}$ My thanks to an anonymous reader for stressing this symmetrical dependence in Lowe's picture of substance. It is worth pointing out that this symmetrical dependence between object and kind is potentially problematic; prima facie, Lowe seems to posit mutual existential dependence between them, and of course that sort of mutual dependence is often seen as problematic (ex. the literature on circular causation). The problem arises precisely because Lowe sees objects and kinds as genuinely, irreducibly distinct, while also affirming moderate (Aristotelian) realism about universals rather than Platonic realism about universals. If he were a Platonist, the circular dependence worry would evaporate, since objects would depend on kinds but kinds would exist eternally and necessarily, independently of objects. Space permitting I would be inclined to argue that Lowe's system is pushed in the direction of admitting uninstantiated universals (for this and other reasons), though I know that would be quite a controversial line to take here.

${ }^{12}$ See (Lowe 2009) for details on his independence account of substance. See also (Koslicki 2013) for a critical treatment of that account and its relation to competing definitions of 'substance'. 
'substance' is a basic ontological category, and an individual substance is simply the instantiation of a substance-universal. A substance-universal is thus not instantiated in or by anything else (like a substratum). ${ }^{13}$ It is worth emphasizing Lowe's substance ontology, insofar as it plays a crucial role in his solution to the unity problem. On his view in fact, the unity problem seems not so much solved as dissolved, rendered inert by reference to his account of modes as ways an individual substance is rather than as constituents out of which a substance is constructed. Diverse inherently separable modes, including essential modes, are 'connected' or 'tied together' only in the sense in which they are all characterizing one and the same object. Likewise, at the level of kinds, diverse inherently separable attributes are linked insofar as they are attributes of one and the same kind. Lowe $(2006,18)$ :

The four-category ontology has no difficulty in saying what 'ties together' the particular properties-that is, the modes-of an object. An object's modes are simply 'particular ways it is': they are characteristics, or features, or aspects of the object, rather than constituents of it. If properties were constituents of an object, they would need, no doubt, to be tied together somehow, either very loosely by coexisting in the same place at the same time, or more tightly by depending in some mysterious way either upon each other or upon some still more mysterious 'substratum', conceived as a further constituent of the object, distinct from any of its properties. It is precisely because a mode is a particular way this or that particular object is that modes cannot 'float free' or 'migrate' from one object to anothercircumstances that pure trope theorists seem obliged to countenance as being at least metaphysically possible. Moreover, the four-category ontology allows us to say that the properties of a kind [i.e., substanceuniversal] are tied to it, in the laws to which it is subject, ${ }^{14}$ in a manner which entirely parallels, at the level of universals, the way in which an individual object's modes are tied to that object. In both cases, the tie is simply a matter of the 'characterization' of a propertied entity by its various properties and consists in the fact that the properties are 'ways' the propertied entity is.

${ }^{13}$ For Lowe's opposition to constituent substance ontologies see especially (Lowe 1998, 2000, 2012, 2013). Other proponents of primitive substance theory include Broackes (2006), Ellis (2001, 2002), Hoffman and Rosenkrantz (1997), Loux (1974, 1978, 2002), and Macdonald (2005).

${ }^{14}$ The reference to 'laws' here should not be misunderstood. For Lowe $(2006,29)$ "a law simply consists-in the simplest sort of case-in some substantial universal or kind being characterized by some non-substantial universal or property, or two or more kinds being characterized by a relational universal." Laws do not explain property unification, but constitute instances of it. Laws thus reduce to facts about kinds. For more on Lowe's ontology of laws see especially (Lowe 1989, chapter8), (Lowe 2001), (Lowe 2006, chapter 8 and 9). 
The idea is that once one understands how objects are related to modes, the unification of the latter, even when they are separable considered in abstraction from the object to which they do actually belong (think again of the mass and charge of an electron) is rendered unproblematic. They are just diverse ways that some one object is, and ipso facto are unified.

Lowe thus sees the kind as a substance-universal that is not intrinsically simple, but rather is complex in just the same way an individual substance is complex, namely, complex in the sense of being characterized in diverse inherently separable ways. He sees it as an unproblematic complexity, insofar as the manner in which an object is characterized by its modes is perspicuous and so the parallel relationship between a kinds and its attributes is likewise perspicuous. Lowe's solution differs here from the Scholastic picture referenced above and advocated by Oderberg $(2007,2011)$. On that view, the relevant substance-universal, or substantial form, is ontologically simple and thus in need of no internal unification. It serves instead as the unifier of the diverse fundamental intrinsic properties associated with it, insofar as its instantiation in prime matter entails the presence of those properties in that prime matter. By contrast, on Lowe's view, the kind is not ontologically simple, but rather is complex in precisely the same sort of way that an individual substance is complex, both being characterized diversely by different attributes (for a kind) or modes (for an object). ${ }^{15}$ Still, both Lowe's account and Oderberg's are versions of priority NKE, insofar as both views maintain that a kind is something in some way distinct from and ontologically prior to the attributes associated with that kind. Lowe (2006, 92-93) makes his commitment to priority NKE (and corresponding rejection of identity NKE) quite explicit, writing that "in my view, a particular thing's being an instance

${ }^{15}$ At this point an anonymous reader asks: "Lowe's kinds are 'qualitatively complex' because of being characterized by distinct attributes. As does Oderberg, Lowe can claim that kinds are mereologically simple and need no internal unification. So, in what exact sense can Lowe's kinds be claimed to be complex in contradistinction with the simple substance universals Oderberg introduces?" This allows for a helpful clarification: for both Lowe and Oderberg, kinds / substantial forms certainly are mereologically simple in the sense that they are not composed of proper parts. On that manner of simplicity, they are agreed. However, for Lowe a kind is internally complex in the sense of being characterized by multiple attributes. By contrast, for Oderberg a kind / substantial form is not literally characterized by any attributes. Rather, a substantial form is a simple, propertyless universal nature whose instantiation primitively guarantees the possession of a certain range of modes by the individual object. For Oderberg, the substantial form does not have attributes, though the individual object instantiating the substantial form does have individual modes, and has them precisely on account of the nature of the form. Space permitting it would be profitable to examine this contrast in greater detail, and the philosophical motivations for Oderberg's insistence on the simplicity of form. However, it would be somewhat tangential to the present discussion. 
of a certain substantial universal can never be 'reduced to', or 'analysed in terms of', that thing's being characterized by modes of certain properties. It may indeed be the case that things of certain kinds necessarily exemplify certain properties, but that does not imply that their being of those kinds simply consists in their exemplifying certain properties." ${ }^{\text {'16 }}$

At this point one might ask: how exactly does the object ground its essential modes (and kinds their essential attributes)? Lowe has described this relationship in terms of modes being ways an object is. Can anything more be said here? Not much. As Lowe (2006, 27-28) writes:

But the properties do indeed need 'support', in the sense that they are ontologically dependent entities which can only exist as the properties of that very individual substance. However, it is the individual substance itself which provides their 'support' in this entirely legitimate sense, and this it can do without the spurious aid of some mysterious 'substratum'. There is no mystery as to how individual substances can perform this 'supporting' role, for once we recognize the category of individual substance as basic and irreducible and the category of property-instance as correlative with it, we can see that their having such a role is part of their essential nature. Explanation-even metaphysical explanation - must reach bedrock somewhere, and this, according to the four-category ontology, is one place where bedrock is reached. The idea that some more fundamental explanation is somehow available, if only we can probe reality more deeply is, I think, just an illusion born of some of the confusions mentioned above. ${ }^{17}$

Thus the dependence / grounding relation between an object and its modes is not capable of much further explication. Modes are entities whose existence and identity are essentially tied up with that of the object to which they belong, and objects are such as to be able to ground modes. What about the object allows it to do this? Simply the nature of the object qua object.

Lowe takes it that the four-category ontology can address not only the unity problem formulated above, but also what might be seen as a related unity problem. That is, one might ask not only why inherently separable essential modes are unified in some object, but also why it is that certain sets of modes are found consistently co-instantiated across diverse distinct objects. He argues that someone who denies the reality of kinds will have a

${ }^{16}$ See also (Lowe 1989, 157): “... a point I take to be of immense importance is that simple natural kind terms are no more definable in terms of lists or clusters of describable characteristics or physical properties than proper names are equivalent to lists or clusters of identifying descriptions."

${ }^{17}$ The confusions he talks about at the end there is chiefly the confusion of taking modes to be constituents of a substance rather than ways it is-that is what bundle theorists do, and so they need a further explanation to explain what links them qua constituents. 
difficult time explaining this consistency across objects, while his ontology makes this situation easily comprehensible (Lowe 2001, 22-23):

But recall that for someone of Martin's persuasion these kinds of particle are not real: that is to say, there are no such substantial universals as electron and proton. There are merely a great many individual particles with various combinations of powers, which we find to fall into certain families by virtue of the resemblances between their powers. ${ }^{18}$ It turns out that a great many of these individual particles have a certain combination of powers-including, say, unit negative charge and a certain distinctive rest mass-and so all of these can be denominated 'electrons'. But we still lack a satisfactory explanation of this situation, which is, prima facie, very remarkable and surprising. Why is it that of all the possible combinations of powers in fundamental particles, only some combinations are found in nature? Why, say, do we not find a particle with the rest mass of the neutron but the charge of the electron? (Again, never mind the scientific accuracy of the example: I use it purely for illustrative purposes.) It seems to me that only someone who takes laws of nature seriously, as involving universals, has an explanation for this state of affairs. We can say that there are certain laws governing the domain of fundamental particles, such as the law that electrons carry unit negative charge and the law that electrons possess a certain distinctive rest mass. Because there are these and other laws concerning one and the same substantial kind-the kind electron-there are individual objects instantiating that kind which exhibit a certain combination of powers and liabilities. Individual fundamental particles exhibiting other possible combinations of powers are not found simply because there are no substantial kinds, governed by appropriate laws, ${ }^{19}$ for any such particles to instantiate.... Someone who denies the reality of universals and laws, other than as arising from resemblances amongst particulars, must, it seems to me, be prepared to accept the existence of enormous and mysterious cosmic coincidences as a matter of brute, inexplicable fact.

The four-category ontology can thus solve not only the unity problem that is our chief concern here, but also a related unity problem having to do with the consistent co-instantiation of modes across objects.

${ }^{18}$ Here Lowe is referring to the nominalist metaphysics of C.B. Martin, according to which there are only two fundamental ontological categories: objects and tropes.

${ }^{19}$ I stress again that for Lowe, laws are reducible to facts about kinds. One must not take this talk of 'governance' too literally in reference to his system. As he says a bit further on (Lowe 2001, 23): "In short, my allegiance to an ontology including both substantial and non-substantial universals, and the laws which consist in certain of the latter characterizing certain of the former, is justified by an inference to best explanation of the order, intelligibility and predictability of the physical universe." 
Hopefully the preceding suffices to convey the basic strategy Lowe employs in addressing the unity problem. In the next section explore a possible critique of this strategy, an then in section four suggest a reply.

\section{An Objection to Lowe's Solution}

Lowe affirms that the object can and does, of itself, serve as unifying ground of / support for its associated modes, and likewise, at the level of universals, that the kind does the same for its attributes. But substratum theorists especially are liable to challenge this picture. Thus consider Martin's (1980) case for substrata. He argues that, of course, an object is an object-withpropertie ${ }^{20}$ and could not exist without properties. It is a unified whole, and the properties are not to be thought of as literal constituents of the object any more than the substratum is. An object is not literally constructed out of properties + substratum (akin to a house being constructed out of bricks and mortar). Rather, properties are modes of an object, that about the object which makes it be a certain way; for instance the red trope is that about the object which makes it red, which provides the truthmaker for the true predication 'that object is red. ${ }^{21}$ As Martin $(1980,8)$ puts it: "It is, then, an error to think of either the substratum of an object or the properties of an object as parts of an object. They are the non-object things about an object." And since an object is not simply a collection of properties, ${ }^{22}$ but rather bears those properties, there likewise must be something about the object which makes it a bearer-of-properties, which provides the truthmaker for the true predication 'that object is a property-bearer'. Substratum theorists reason that the object itself, the object as a whole (i.e., the object qua propertied), cannot be that truthmaker. The reason is that the object as a whole is propertied, and the propertied-object cannot account for the object's bearing of properties, since its status qua propertied is precisely what is calling out for explanation. In other words, referencing the object as a whole, the object qua propertied, as truthmaker for its bearing of properties (or grounding of properties or support of properties), is circular. In fact, arguably that claim (that the propertied substance accounts for its being a property-bearer) does

${ }^{20}$ Note that Martin is a nominalist, so when I use 'properties' in referring to his account, I mean tropes. However, his nominalism can be left to one side for present purposes.

${ }^{21}$ Other prominent substratum theorists like Armstrong $(1989,97)$ are likewise fine with talking about properties as modes. He brings this up in the context of an argument against bundle theory: "My contention is that once properties and relations are thought of not as things, but as ways, it is profoundly unnatural to think of these ways as floating free from things. Ways, I am saying, are naturally construed only as ways actual things are or ways actual things stand to each other."

${ }^{22}$ Indeed Martin takes bundle theorists to be fundamentally confused, mistaking the ontological category of 'proper part' for the ontological category 'property'. 
not even rise to the level of explanation, since nothing about the object has been identified as the distinct truthmaker for its being a property-bearer. Hence recourse must be made to substrata.

This is clearly a direct challenge to Lowe's claim that the object's nature $q u a$ object suffices as truthmaker for its grounding of properties. To this challenge, Lowe and other primitive substance theorists might reply that an object's being a bearer of properties is just not the sort of fact that admits of further explanation. To repeat a portion of Lowe $(2006,27-28)$ cited in the previous section: "There is no mystery as to how individual substances can perform this 'supporting' role, for once we recognize the category of individual substance as basic and irreducible and the category of property-instance as correlative with it, we can see that their having such a role is part of their essential nature. Explanation-even metaphysical explanation-must reach bedrock somewhere...." In fact Lowe $(2000,513)$ replies directly to Martin's account: "But why suppose that the subject of inherence is anything other than the very object whose qualities is 'supports'? And why, indeed, suppose that there is a genuine relation, one of 'support', between substratum and quality?"23

To that Martin might in turn reply: even the primitive substance theorist must him/herself think of the subject of inherence as other than the objectas-a-whole (i.e., the object qua propertied), not only to avoid circularity in explanation, but also because the primitive substance theorist believes that the object has ontological priority over its modes. As we saw earlier, Lowe affirms that the latter depend on the former both for their existence and their identity. In this way, primitive substance theorists are committed to the idea that an object is a genuine reality genuinely distinct from its modes (just as, at the level of the substance-universal, kinds are genuinely distinct from their attributes). On this point, consider another advocate of primitive substance theory, (Broackes 2006, 149), who writes: "Tibbles [the cat] has properties... and he is distinct from his properties, in the sense that he is not identical with any or all of them... But that does not imply that Tibbles and his properties are separable, in the sense that each could be detached from the other (leaving subject without properties, and the properties without a subject)." They may well not be separable; indeed most substratum theorists claim that a substratum cannot exist on its own, failing to instantiate any properties. ${ }^{24}$ But if an object is not identical to its modes (individually

${ }^{23}$ Lowe (2000, 513, footnote 22) here provides a footnote worth relating (ibid.): "Martin does clearly think that such a relation exists, even though he says that 'The relation between substrata and properties is not like other relations... because it stands between things about or ingredients of objects and not between objects themselves"'

${ }^{24}$ The main dissenter on this in the recent literature is (Sider 2006). 
or collectively) just what is it? What is there in addition to the modes supposedly characterizing this thing, such that the modes are grounded? The substratum theorist will argue that the primitive substance theorist, in trying to answer this, will inevitably be driven to an admission of substrata.

To tie this back to our concern with the unity problem: the primitive substance theorist can only solve that problem by reference to his/her substance ontology if the object is real and irreducible to its modes, and ontologically prior to them. But priority and irreducibility implies real distinction (even if not separability). Thus the object is in some sense genuinely distinct from its modes. And if that is the case, it is not immediately clear how primitive substance theory can avoid falling into substratum theory; for if the object as a whole, the object-qua-propertied, is not genuinely distinct from its modes (clearly it is not, since it explicitly includes them), there must be something about that object which is thus distinct, such that the relevant ontological priority can be preserved. According to the substratum theorist, it is precisely the substratum that fills this role. Consequently, it is not immediately clear how the primitive substance theorist's solution to the unity problem can avoid being reduced to the solution provided by substratum theorists: namely, diverse inherently separable modes are conjoined because they all belong to one and the same substratum.

At this stage of the dialectic, the proponent of Lowe's view might counter that there must be something amiss with the substratum theorist's solution to the unity problem, since even if it can address that problem, it cannot address the related unity problem alluded to towards the end of the previous section; that is, it cannot address the issue of how it is that consistent property coinstantiations are found across multiple objects. Lowe's ontology of kinds explains this, but how could substratum theory deal with it?

Martin $(1980,7)$ does in fact have something to say regarding the relationship between substrata and the ontology of kinds: "A substratum qua substratum is that about an object that is the bearer of properties.... If a set of properties is specified making up a kind and it is attributed to a substratum, then the resultant is an object that is an object of a kind. The substratum will be that about the object that is the bearer of properties. What properties the substratum bears will not determine what the substratum is qua substratum, but will determine what kind the object is." Of course, this does not shed much light on this and unity problem, except to indicate that Martin is open to a certain sort of realism about kinds. Clearly the view he is thinking of is identity NKE rather than priority NKE, as he considers that a set of properties makes up a kind. Still, priority NKE (with its realism about universals) is not obviously inconsistent with substratum theory. In theory then, one might hold to substratum theory, in part because of the solution it 
furnishes to the unity problem, while also holding to some form of priority NKE (whether Lowe's or Oderberg's or some other version) to solve the 2nd unity problem. As a matter of fact though, the one substratum theorist who has taken up this question in detail, namely Armstrong (1997), rejects this solution. He is a reductionist about natural kinds, and addresses the 2nd unity problem not by reference to realism about kinds, but rather by reference to a robust nomic realism. Thus on his view diverse universals get unified in a single object because of their being co-instantiated in one and the same substratum, while consistent property co-instantiations across objects are explained by reference to contingent laws of nature that connect those properties in just that way. ${ }^{25}$ One might of course dispute the ability of external laws of nature to shed light on this, perhaps on the ground that external governing laws are problematic in various ways. ${ }^{26}$ But what is important for present purposes is simply that the substratum theorist has relevant options available to him / her that do not necessarily require reference to something like Lowe's ontology of kinds.

With the objection having been laid out, and certain possible avenues of reply rejected, I would like now to suggest an additional reply that may fare better.

\section{A Reply on Behalf of Lowe}

The present difficulty arises from Lowe's commitment to the claim that both objects and modes (and correspondingly kinds and attributes) are genuinely real, and to the claim that objects are ontologically prior to modes. Genuine distinction and priority are needed to run Lowe's solution to the unity problem, but it is genuine distinction and priority that also seem to push Lowe's ontology in the direction of substratum theory. One way around the objection then would be to affirm the ontological priority of substance while reconceiving modes (and attributes) in such a way that they are reducible, in a sense, to the object (and kind).

At first glance that suggestion is liable to seem radically antithetical to Lowe's system. Certainly the existing ontologies that adopt a comparable suggestion are thus antithetical. I think here of austere nominalism, on the

${ }^{25}$ Psillos $(2009,120)$ entertains a similar thought, seeming to reference laws as explaining both unity problems: “.. why is it the case that some causal powers go together and others do not? Why do certain powers have a certain kind of 'causal unity'...? This is a crucial question...the concurrence of certain powers might well be the consequence of a law. It might well be that laws hold some capacities together. Hence, it seems that we cannot do with just capacities. We also need laws as our building blocks."

${ }^{26}$ See especially (Mumford 2004) for a critique of robustly realist ontologies of law. See also (Oderberg 2011, 90-92) on the specific question of whether such ontologies can be of any help in addressing the unity problem. 
one hand, and Platonic relational substance ontology on the other. Loux (2002, 98) summarizes austere nominalism as follows:

\begin{abstract}
Since they deny that there are such things as attributes, the austere nominalists see concrete particulars as unanalyzable entities, as things that have no ontological structure.... As the austere nominalist sees things, there is just the concrete particular. On this view, concrete particulars are what David Armstrong appropriately calls 'blobs'completely unstructured wholes. They are, of course, things that can have a plurality of distinct physical parts; but, for the austere nominalist, those physical parts are like the wholes whose parts they are in being utterly opaque to metaphysical analysis.
\end{abstract}

The austere nominalist denies the reality not only of properties conceived as universals, but even of tropes. Advocates of Platonic relational substance ontology are realists about universals, thus differing in an important respect from the austere nominalist. However, on their view these universals cannot properly be said to be instantiated 'in' or 'by' individual objects. They do not in any sense enter into the constitution of the object. Rather, the object is related to the utterly transcendent universal in some way, by 'participation' or 'imitation'. In consequence of that relation the universals can be predicated of the object, yet they remain radically separate. Lowe (2012, 233-234) summarizes the Platonic view:

According to this approach, at least as I shall be interpreting it here, features and forms do not reside within the concrete objects that are said to 'possess' them, as constituents of those objects, but instead exist 'separately' from the concrete world, serving as immutable and eternal patterns for concrete objects to exemplify or imitate, usuallyor perhaps even always-only imperfectly. On this view, the concrete objects themselves... are not ontologically complex, except inasmuch as they contain other such objects as parts, and there is nothing 'in' them corresponding to the features and forms they are said to exemplify. Those features and forms are one and all universals, each being exemplifiable, at least in principle, by a plurality of different concrete objects. In saying that there is nothing 'in' the objects corresponding to those features and forms, I mean to exclude the idea that those objects possess particular features and forms, answering to or 'resembling' the universal features and forms that they exemplify... Concrete objects, on this view, are in themselves featureless and formless 'blobs', which can be described as 'having' certain features and forms only in a derivative or relative sense, to the extent that they primitively resemble to some degree some universal feature or form.

The similarity between the two views, despite their difference concerning the reality of universals, is made clear in that Loux and Lowe both employ 
the 'blob' analogy in their respective summaries. And Lowe's system is opposed to both; its opposition to austere nominalism is obvious given Lowe's moderate (Aristotelian) realism. He also explicitly rejects the Platonic relational view (Lowe 2012, 234): "The troubles with the transcendent approach are many, both metaphysical and epistemological, and I shall only scratch the surface of these. First, it simply is not clear how an inherently featureless and formless 'blob'-which is what a concrete object is, on the present view-could 'resemble' some universal feature or form. For, in the nature of the case, there could be nothing in virtue of which it could resemble one." Thus, while both austere nominalism and Platonic relationism each solve the unity problem by preventing it from ever getting off the ground (since on both views objects do not have fundamental intrinsic properties), both are inimical to Lowe's four-category ontology. Consequently, one might think that any proposal for the elimination or even reduction of modes to objects (and attributes to kinds) would automatically fall afoul of that ontology's central commitments.

However, I think one sort of reductionist view might actually accord with Lowe's ontology. Rather than eliminating modes altogether (and, at the level of universals, attributes), the idea I want to canvass is that modes be reconceived. That is, a mode should be thought of not as a positive entity borne by the object (which is how everyone from substratum theorists to primitive substance theorists to bundle theorists typically conceives them), but simply as the object itself qua limited / circumscribed / bounded in a determinate fashion. Limitations are real in a sense-a physical object has a determinate spatial boundary. But that boundary is not a positive entity added to the object or borne by the object; rather, it is just the object qua limited in a certain way. This limitation thus properly counts as a mode (it is, after all, a way that object is), yet it is not in any sense a positive addition to the object. And in fact any geometrical / structural property seems capable of reconceptualization in this manner. Thus think of an object's determinate shape. Does it make sense to think of shape as some extra, positive entity added to the object? No. The object's shape just is the object, the object qua bounded / limited / circumscribed in a certain determinate fashion. The same goes for size, length, breadth, and all the other paradigm structural properties. They are all modes, but modes properly conceived not as additions to the object they characterize, but as reducible to that object qua limited in some way. They are limits on an object, or one might even say negations of the object. They are real and ineliminable, and needed as truthmakers for certain sorts of true statements about the object, but they are real only in the manner in which a doughnut hole is real, being merely a certain determinate absence / negation / circumscription of a concrete particular, and thus in a sense re- 
ducible to that particular. Note too that a limitation is not strictly identical to what is being limited; a doughnut hole is not a doughnut. Thus Lowe's commitment $\mathrm{o}$ to the real distinction between a substance and its modes is preserved. $^{27}$

If someone were to affirm that all intrinsic properties are geometrical / structural in nature (a position which has certainly had its share of advocates), then the objection discussed in the previous section would automatically be seen to have no purchase. The reason is that now the ontological priority of an object over its modes, and the real distinction between them, in no way endangers primitive substance theory or its solution to the unity problem. For it is clear how the object itself 'grounds' its modes, and does so without any need to reference a distinct substratum: namely, it grounds its modes in the sense that its modes just are the object qua negated in a certain fashion. On this view, the unity of those modes becomes unproblematic; a thing's limitations / boundaries, even if somehow inherently separable, are clearly unified by being limits of one and the same object. ${ }^{28}$ Moreover, because an object's limits / boundaries etc. can change while the overall identity of the object is preserved, the contingency of at least some modes is preserved.

Of course, Lowe does not believe only in geometrical / structural modes; he affirms the reality of dispositions as well. Consequently the reductionist story I'm pushing here needs some further elaboration. How might a dispositional property be conceived as a determinate limitation / negation of a substance? To begin answering this, we need to examine Lowe's unique conception of dispositions. For him, the dispositional / categorical distinction does not actually represent a distinction between two irreducible types of property, but rather two types of predication (Lowe 2001, 8-10):

I have already indicated that I am opposed to drawing a distinction between dispositional and categorical (or occurrent) properties, as though what is at issue here is a distinction between types of property. Rather, I want to distinguish between dispositional and (as I prefer to

\footnotetext{
${ }^{27}$ That being the case, 'reduction' is perhaps not the best term to use for the relationship being discussed, since many (though certainly not all) take reduction to involve a strict identity claim. Still, there seems a dearth of terms available to describe quite the relationship meant; perhaps 'reduction' is as good as any other.

${ }^{28}$ Something like this reductionism or deflationism about modes (or at least certain sorts of modes) has ample historical precedent in the middle ages (for instance Aquinas and Ockham) and early modern period (for instance Hobbes). For detailed discussion see (Pasnau 2011, especially chapters 10 and 14). A note of terminological caution though: what Lowe means by 'mode', Pasnau means by 'accident'. By contrast, 'mode' in Pasnau's work is a technical term for something quite different (i.e., something other than Lowe's modes).
} 
call it) occurrent predication. And, as I have already remarked, not every predicate expresses a corresponding existent property. The distinction in question is exhibited in such pairs of sentences as 'This piece of rubber is stretchy' and 'This piece of rubber is stretching', or 'This stuff dissolves in water' and 'This stuff is dissolving in water'. Now, my view is that, even when a predicate does express a real property, it expresses one and the same property (in the sense of universal) irrespective of whether the predication involved is dispositional or occurrent in character.... Consider, then, properties of shape and colour, which many philosophers regard as paradigm examples of categorical and dispositional properties respectively.... I would urge that each of the predicates 'is square' and 'is red' has both a dispositional and an occurrent interpretation. Thus, I suggest, a surface which 'is red' in the dispositional sense is one which, nevertheless, is not red, in the occurrent sense, in a darkened room or under blue light: in those circumstances, I suggest, the surface is grey or black in the occurrent sense. If we used verbs instead of adjectives to express colour, as some languages do, this would be more obvious. We could then render more explicit the distinction between occurrent and dispositional senses of our ambiguous colour predicate 'is red' by saying that a surface which is not redding under blue light may nonetheless be a reddy surface-just as we say that a piece of rubber which is not stretching may nonetheless be stretchy. Equally I think that a surface can be both occurrently and dispositionally square-but, again, that this should not be conceived as a distinction between different types of property of the surface. For example, a rubber eraser may be 'square' in the dispositional sense while also being 'trapezoid', say, in the occurrent sense, when it is subjected to certain distorting stresses.

On Lowe's perspective, occurrent predication thus involves the claim that some object is characterized by a mode, whereas dispositional predication involves the claim that some kind is characterized by an attribute. Thus to say that an individual piece of salt is dissolving is to claim that a mode characterizes it, whereas to say that salt is soluble is to claim that a kind is characterized by an attribute, namely the attribute dissolving. The latter predication is dispositional, the former occurrent. It is important to note here that for Lowe, activities / processes / events belong to the category of modes (when engaged in by particulars) and attributes (when engaged in by kinds). $\mathrm{He}$ does not recognize a distinct, fundamental ontological category of process or activity. ${ }^{29}$

How is this relevant to present concerns? Well, here again we have a conception of modes whereby the mode is clearly not some addition to the

${ }^{29}$ In this he differs from other natural-kind essentialists, like Ellis (2001, 2002, 2005), whose six-category ontology includes (besides the four adopted by Lowe) individual processes and process-universals. 
object or something literally borne by the object. That is not the sort of relationship that an activity has to the entity engaged in that activity. Rather, in this case the relevant mode is reducible to the object itself qua active or (when dispositional predication is applied) qua instantiating an inherently active kind. An individual object, even if currently inactive in some respect, can be said to be disposed to some activity if the kind which it instantiates is intrinsically engaged in that activity (in the abstract, atemporal fashion appropriate to a universal).

Thus a kind is intrinsically active, and since an object just is the instantiation of a kind, presumably for Lowe an object is also intrinsically active. But of course an object typically cannot manifest all of those activities characteristic of its kind simultaneously, since some of those activities are liable to be incompatible when considered in terms of temporal simultaneity. I as an individual object cannot carry out the activities 'running' and 'making toast' at the same time, even though both activities are attributed to the kind 'human being, and so apply to the object in the form of dispositional predications. Consequently, what we normally think of as a dispositional property would amount to an inherently active object whose activity is limited / circumscribed / determinately channeled by external causal factors, such that only one or a limited number of activities characteristic of the kind it instantiates are presently carried out by the object. From this perspective, the stimulus of a disposition is reconceived as something that removes a barrier to the object's outwardly manifesting some intrinsic activity characteristic of its kind, perhaps by preventing other incompatible activities from being carried out. The stimulus does not bring to life an otherwise inert object-rather, it limits / channels activities it is already intrinsically engaged in.

For instance, consider fragility (hardly a fundamental disposition, but widely used in thought experiments concerning dispositions). An object's breaking apart might be conceived as the stimulation of a power-for-breaking in a previously inert object. But it might likewise be reconceived as the interruption / limitation / circumscription of the bonding activity being carried out by the object (or the object's proper parts), which limitation results in breaking and also entails that certain other incompatible activities (such as dissolving) are not being carried out at that same time. Or consider my power to run and my power to stand still. Both 'running' and 'standing still' are attributes of the kind 'human being. But when that kind is instantiated as an object, it is not the case that both activities can be carried out simultaneously. Thus there must be some external causal factor that channels the inherent activities of the object in such a way that only one of those activities (or some other activity) is realized at a time, a factor that explains the determinate limitation of activities manifested by that object. Again, on this 
view, the stimulus that results in what we normally think of as a dispositionmanifestation is a causal factor that limits / circumscribes / channels intrinsic activities in some way-the stimulus is not a causal factor that prompts activity in an otherwise inert object.

This way of looking at dispositions is rather a radical departure from typical dispositionalist thinking; certainly, it is usually assumed that activities are grounded in ontologically prior causal powers, not the other way around. But Lowe's ontology of dispositions is itself already a radical departure from the standard dispositionalist line, so at worst the present suggestion just renders his ontology a bit more radical. And the situation is arguably helped by the fact that there are good, wholly independent reasons for thinking that at least some activities are intrinsic to an object, that not all activities are grounded in dispositions. Dumsday (2012) makes a case for this, thereby lending some additional background support to Lowe's ontology of dispositions and the additional reconceptualization suggested here.

If this proposal is at all workable, such that all modes are considered reducible either to objects qua determinately limited (in the case of geometri$\mathrm{cal} /$ structural modes) or to objects qua intrinsically active and instantiating intrinsically active kinds (in the case of dispositions), it would furnish the primitive substance theorist with ammunition against the charge of being pushed into substratum theory. For now the object is explicitly conceived as related to its modes not as a pincushion is to its pins but more as a hunk of marble to the shape that now constitutes it as the specific statue it is, precisely by constituting a boundary / determinate limitation on the marble. ${ }^{30}$ An object is conceived as having modes, but not in any way that we would be tempted to think of the substance as having some underlying, bare constituent like a substratum.

Furthermore, if this proposal is workable it may also shed some light on how to respond to Heil's $(2012,115-116)$ critique of Lowe on dispositions:

Consider this electron, $e$. Let us suppose that electrons annihilate when they encounter a positron. So $e$ is disposed to annihilate on encountering a positron. This will be the case, even if $e$ never encounters a positron. But now the electron kind is supposed to possess the property of annihilating in concert with a positron. It, the kind,

${ }^{30}$ Scholastic readers will likely perceive a parallel between this proposal and the view (defended by so-called 'existential' Thomists like Clarke 2001) of essence as determinate limit on existence. I would be inclined to think that ultimately one might have to transition from parallel to equivalence, insofar as substance is understood most fundamentally as an independent existent. Demonstrating that equivalence would require some work though. Such a proposal would also involve an affirmation of the ontological priority of existence over essence, an idea Lowe resists in (Lowe 2008, 40). 
doesn't possess this property dispositionally; we are offering an explanation of dispositionality. So the electron kind is annihilating. Well and good, but it is also repelling other electrons and doing much else besides. the picture here is of the kind as being God-like: wholly 'in act'. A kind is doing all its instances could do. As the electron example suggests, one reason this might be hard to swallow is that some of what an instance of a kind would do apparently exclude its doing other things. An electron would repel other electrons. Presumably, then, the electron kind is 'characterized by' repelling electrons. But an electron would annihilate were it to encounter a positron. So the kind electron, in addition to repelling other electrons, is annihilating. I don't want to say that this picture is impossible, but I admit I do not understand it. I do not see how a kind could be, timelessly perhaps, characterized by apparently incompatible properties.

The force of this objection is muted when one simply admits that kinds, considered as universals, are atemporal entities that in fact admit of incompatible activity-predications. Objects, the instantiations of those kinds, inherit their intrinsic activities, but they do so in such a way that their activities are bounded / limited / circumscribed and incompatible activities are not carried out by the same object simultaneously.

If geometrical / structural properties and dispositions are the only two irreducible categories of modes / attributes, then not much more needs to be said. But what of qualitative properties? Well, the paradigm case of a qualitative property is colour, and it is widely assumed that colour is reducible to a disposition or set of dispositions (a power to reflect light in a certain way combined with a power of some organism's visual system to register this etc.). If all qualitative properties are thus reducible to dispositions, and dispositions can be handled in the manner suggested above, then there will be no difficulty here. For reasons of space I cannot at present make the case that all qualitative properties are in fact reducible to dispositions, but of course such arguments have been made.

\section{Conclusion}

It may be that the position just developed in reply to the objection made in section 3 above is not the only way to address that objection, nor the only way for a primitive substance theorist and natural-kind essentialist to address it. Earlier I referenced the work of Oderberg and other Scholastics; arguably their conception of kinds as substantial forms allows for a different reply to the objection, one that does not risk falling into substratum theory and does not automatically necessitate the reductionist strategy I have just outlined. However, as we have seen, the Scholastic account of the unity problem does involve some reference to prime matter, which, while importantly different 
from the notion of a substratum, ${ }^{31}$ is analogous in some ways and liable to be resisted by primitive substance theorists like Lowe. In fact Lowe explicitly rejects prime matter in (Lowe 1998) and (Lowe 2013). At any rate, another useful item for future research would be a detailed compare / contrast study between the approach to the unity problem taken by Lowe and that taken by one or more of the mainstream Scholastic systems, and a comparison of the distinct problems faced by those differing approaches.

To sum up: the unity problem is a longstanding one that has played a role in shaping both substance ontology and natural-kind essentialism. Lowe's solution to that problem deserves close attention; and though it is apparently vulnerable to an objection arising out of the substratum theorists' camp, that objection may admit of a reply that accords with Lowe's system, even if involving a reconceptualization of the nature of modes as determinate limitations (whether of structure or activity). And if that reconceptualization is adopted, there may be a fringe benefit insofar as it could shed light on how to address a different concern raised for Lowe's system by Heil (2012).

\section{Acknowledgements}

My sincere thanks to an anonymous reader and to Riin Sirkel for helpful comments, and to Tuomas Tahko for the kind invitation to contribute to this special issue of Studia Philosophica Estonica.

\section{Bibliography}

Armstrong, D. (1989). Universals: An Opinionated Introduction, Westview, Boulder.

Armstrong, D. (1997). A World of States of Affairs, Cambridge University Press, Cambridge.

Broackes, J. (2006). Substance, Proceedings of the Aristotelian Society 106: 131-166.

Clarke, W. (2001). The One and the Many: A Contemporary Thomistic Metaphysics, University of Notre Dame Press, Notre Dame.

Connell, R. (1966). Matter and Becoming, The Priory Press, Chicago.

Dumsday, T. (2010). Natural kinds and the problem of complex essences, Australasian Journal of Philosophy 88: 619-634.

${ }^{31}$ For reasons of space I will not delve into those differences here. 
Dumsday, T. (2012). Dispositions, primitive activities, and essentially active objects, Pacific Philosophical Quarterly 93: 43-64.

Ellis, B. (2001). Scientific Essentialism, Cambridge University Press, Cambridge.

Ellis, B. (2002). The Philosophy of Nature: A Guide to the New Essentialism, McGill-Queen's University Press.

Ellis, B. (2005). Universals, the essential problem and categorical properties, Ratio 18: 462-472.

Gorman, M. (2005). The essential and the accidental, Ratio 18: 276-289.

Heil, J. (2012). Are four categories two too many?, in T. Tahko (ed.), Contemporary Aristotelian Metaphysics, Cambridge University Press, Cambridge, pp. 105-125.

Hoffman, J. and Rosenkrantz, G. (1997). Substance: Its Nature and Existence, Routledge, London.

Koslicki, K. (2013). Substance, independence, and unity, in E. Feser (ed.), Aristotle on Method and Metaphysics, Palgrave Macmillan, New York, pp. 169-195.

Kronen, J. (1991). Essentialism old and new: Suarez and Brody, Modern Schoolman 58: 123-151.

LaBossiere, M. (1994). Substances and substrata, Australasian Journal of Philosophy 72: 360-370.

Loux, M. (1974). Kinds and the dilemma of individuation, Review of Metaphysics 27: 773-784.

Loux, M. (1978). Substance and Attribute: A Study in Ontology, Reidel, Dordrecht.

Loux, M. (2002). Metaphysics: A Contemporary Introduction, 2nd edn, Routledge.

Lowe, E. (1989). Kinds of Being: A Study of Individuation, Identity and the Logic of Sortal Terms, Blackwell, Oxford.

Lowe, E. (1997). Ontological categories and natural kinds, Philosophical $\mathrm{Pa}$ pers 26: $29-46$.

Lowe, E. (1998). Form without matter, Ratio 11: 214-234.

Lowe, E. (2000). Locke, Martin, and substance, Philosophical Quarterly 50: $499-514$.

Lowe, E. (2001). Dispositions and laws, Metaphysica 2: 5-23.

Lowe, E. (2006). The Four-Category Ontology: A Metaphysical Foundation 
for Natural Science, Oxford University Press, Oxford.

Lowe, E. (2008). Two notions of being: Entity and essence, Philosophy 83: 2348.

Lowe, E. (2009). Ontological dependence, in E. N. Zalta (ed.), Stanford Encyclopedia of Philosophy, fall 2009 edn.

URL:http://plato.stanford.edu/archives/fall2oog/entries/ dependence-ontological/

Lowe, E. (2012). A neo-Aristotelian substance ontology: Neither relational nor constituent, in T. Tahko (ed.), Contemporary Aristotelian Metaphysics, Cambridge University Press, Cambridge, pp. 229-248.

Lowe, E. (2013). Neo-Aristotelian metaphysics: A brief exposition and defense, in E. Feser (ed.), Aristotle on Method and Metaphysics, Palgrave Macmillan, New York, pp. 196-205.

Macdonald, C. (2005). Varieties of Things: Foundations of Contemporary Metaphysics, Blackwell.

Martin, C. (1980). Substance substantiated, Australasian Journal of Philosophy 58: 3-10.

Mumford, S. (2004). Laws in Nature, Routledge, New York.

Oderberg, D. (2007). Real Essentialism, Routledge, London.

Oderberg, D. (2011). Essence and properties, Erkenntnis 75: 85-111.

Pasnau, R. (2011). Metaphysical Themes: 1274-1671, Oxford University Press, Oxford.

Psillos, S. (2009). Knowing the Structure of Nature: Essays on Realism and Explanation, Palgrave Macmillan, New York.

Scaltsas, T. (1994). Substances and Universals in Aristotle's Metaphysics, Cornell University Press, Ithaca.

Sider, T. (2006). Bare particulars, Philosophical Perspectives 20: 387-397.

Williams, S. and Charles, D. (2013). Essence, modality, and the master craftsman, in E. Feser (ed.), Aristotle on Method and Metaphysics, Palgrave Macmillan, New York, pp. 121-145. 